\title{
RESPOSTA DA PRODUTIVIDADE DO ALGODOEIRO EM DIFERENTES DOSES DE NITROGÊNIO E EFICIÊNCIA DO SENSOR ÓPTICO EM ESTIMAR O POTENCIAL PRODUTIVO
}

Leandro Ricardo de Nadai Geib ${ }^{1}$, Telmo Jorge Carneiro Amado ${ }^{2}$, Jardes Bragagnolo ${ }^{3}$, Rafael Pivotto Bortolotto ${ }^{4}$, Douglas Dalla Nora ${ }^{5}$

\section{RESUMO}

O desenvolvimento da cultura do algodoeiro é diretamente influenciado pela nutrição nitrogenada, a qual é dependente da fertilização mineral. No entanto, o manejo do nitrogênio nesta cultura é complexo, uma vez que doses elevadas também podem provocar efeitos negativos na produtividade da cultura. Nesse contexto, o ajuste fino na dosagem de $\mathrm{N}$ fertilizante, de acordo com a demanda da cultura, é essencial para a obtenção de elevadas produtividades. O presente trabalho teve como objetivos: I - estabelecer a curva de resposta de produtividade do algodoeiro ao N fertilizante; II avaliar a capacidade do sensor óptico em estimar o potencial produtivo. O experimento foi conduzido no ano agrícola de 2012/13 em um Latossolo Vermelho Amarelo, no oeste do estado da Bahia, em três áreas sob clima tropical, com precipitação anual de $1600 \mathrm{~mm}^{2} \mathrm{ano}^{-1} \mathrm{e}$ temperatura média anual em torno de $21^{\circ} \mathrm{C}$. O delineamento experimental foi em blocos ao acaso, com sete tratamentos e três repetições. Os tratamentos consistiram nas seguintes doses de N: 0, 45, 90, 130, 150, 180 e $220 \mathrm{~kg} \mathrm{ha}^{-1}$, aplicadas aos 43 dias após a semeadura (DAS) na área 1 e aos 32 DAS nas áreas 2 e 3. As leituras de IV foram realizadas em três épocas, correspondentes aos 63, 75 e 97 DAS na área 1 e aos 45,57 e 80 DAS nas áreas 2 e 3, utilizando o sensor óptico N-Sensor ALS ${ }^{\circledR}$ (YARA). Adjacente aos estádios e pontos de leitura de IV, foi realizada a determinação de produtividade do algodoeiro. A produtividade da cultura do algodoeiro apresentou um ajuste quadrático com as doses de $\mathrm{N}$ nos três experimentos estudados e a dose que atingiu a máxima eficiência econômica foi a de 164, 139 e $167 \mathrm{~kg} \mathrm{ha}^{-1}$ de $\mathrm{N}$ para as áreas 1, 2 e 3, respectivamente.

Palavras-chave: Sensor, Estádio fenológico, Índice de vegetação, Gossypium hirsutum L.

\section{ABSTRACT \\ RESPONSE OF COTTON PRODUCTIVITY SUBMITTED TO DIFFERENT DOSES OF NITROGEN AND EFFICIENCY OF THE OPTICAL SENSOR TO ESTIMATE YIELD POTENTIAL}

The development of the cotton crop is directly influenced by nitrogen nutrition, which is dependent on mineral fertilization. However, the management of nitrogen by this culture is complex, since large doses can also cause negative effects on crop yield. In this context, fine-tuning the dosage of $\mathrm{N}$ fertilizer, according to the crop demands, is essential to obtain high yields. This study sought to: I - establish the response curve of cotton yield to N fertilization, II - evaluate the capability of the optical sensor to estimate yield potential. The experiment was conducted in the agricultural year 2012/13 in an Oxisoil in the western region of the state of Bahia, in three areas with tropical climate, annual rainfall of $1600 \mathrm{~mm}$ $\mathrm{yr}^{-1}$ and a mean annual temperature of around $21^{\circ} \mathrm{C}$. The experiment was setup in a randomized block design with seven treatments and three replications. The treatments consisted of the following $\mathrm{N}$ doses: $0,45,90,130,150,180$ and $220 \mathrm{~kg}$ $\mathrm{ha}^{-1}$ applied at 43 days after sowing (DAS) in area 1 and 32 DAS in areas 2 and 3. The vegetation index (VI) readings were taken at three different times, corresponding to 63, 75 and 97 DAS in area 1 and 45, 57 and 80 DAS in areas 2 and 3, using the optical sensor N-Sensor ALS ${ }^{\circledR}$ (YARA). For the different areas and VI readings the cotton yield was determined. The productivity of the cotton crop showed a quadratic fit with $\mathrm{N}$ doses studied in three experiments and the rates which achieved maximum economic efficiency were 164, 139 and $167 \mathrm{~kg} \mathrm{ha}^{-1}$ of $\mathrm{N}$ for areas 1,2 and 3, respectively.

Keywords: Sensor, phenological Stadium, vegetation index, Gossypium hirsutum L.

\section{Recebido para publicação em 16/04/2014. Aprovado em 23/10/2014.}

1 - Eng. Agrônomo, Mestrando, Depto. de Eng. Agrícola, Universidade Federal de Santa Maria (UFSM), leandrodenadai@gmail.com)

2 - Professor Titular, Bolsista CNPq Departamento Solos, Universidade Federal de Santa Maria (UFSM)

3 - Engenheiro Agrônomo, Doutor, Departamento de Solos; Universidade Federal de Santa Maria (UFSM)

4 - Engenheiro Agrônomo, Doutor, Departamento de Solos; Universidade Federal de Santa Maria (UFSM)

5 - Engenheiro Agrônomo, Mestrando, Departamento de Solos, Universidade Federal de Santa Maria (UFSM) 


\section{INTRODUÇÃO}

O nitrogênio $(\mathrm{N})$ geralmente é um dos principais fatores limitantes à produtividade do algodoeiro (Gossypium hirsutum L.). Segundo Staut e Kurihara (2001), o N é fundamental no desenvolvimento da planta, principalmente para os órgãos vegetativos. Segundo Rosolem, Zancanaro e Tessaro (2007), a exportação de $\mathrm{N}$ pelo algodoeiro é de 50 a $85 \mathrm{~kg}$ de $\mathrm{N}$ para produzir uma tonelada de algodão em caroço, dependendo da variedade e das condições edafoclimáticas.

A determinação da dose de $\mathrm{N}$ no algodoeiro é uma decisão complexa. Pesquisas evidenciam distintas respostas da cultura quanto à aplicação de N, e trabalhos realizados por Silva et al. (1993) reportaram que doses acima de $70 \mathrm{~kg} \mathrm{ha}^{-1}$ não seriam econômicas. No entanto, Filho e Pedrosa (2004) observaram, em anos com maior precipitação, respostas à dose de $140 \mathrm{~kg} \mathrm{ha}^{-1}$.

Para expectativas de produtividade de 5000 $\mathrm{kg}$ ha ${ }^{-1}$, Carvalho et al. (2007) preconizaram o uso de $20-25 \mathrm{~kg} \mathrm{ha}^{-1}$ de $\mathrm{N}$ na semeadura e $125 \mathrm{~kg}$ ha $^{-1}$ em cobertura. De acordo com o Ministério da Agricultura, Pecuária e Abastecimento (MAPA, 2006), é recomendada a aplicação de 120 a $130 \mathrm{~kg}$ de ha ${ }^{-1}$ de $\mathrm{N}$ em solos argilosos e de $150 \mathrm{~kg} \mathrm{ha}^{-1}$ de $\mathrm{N}$ em solos arenosos, parcelando as aplicações em 15-30 kg ha-1 na semeadura e o restante em duas aplicações em cobertura, sendo a primeira aplicação entre os 25-30 dias após a emergência (DAE) e a segunda aos 55-60 DAE, no estádio F1.

$\mathrm{O} \mathrm{N}$, quando aplicado em doses adequadas, estimula o crescimento e o florescimento do algodoeiro, aumentando a produtividade e melhorando a qualidade da pluma (STAUT; KURIHARA, 2001). Nesse sentido, quando constatada a deficiência de $\mathrm{N}$ no início do florescimento, ocorre um retardamento no ciclo da cultura (MALIK et al., 1978). Da mesma maneira, Hutmacher et al. (2004) afirmaram que doses excessivas de $\mathrm{N}$ estimulam demasiadamente o crescimento vegetativo e, consequentemente, há diminuição da qualidade da pluma. Portanto, a deficiência ou o excesso de $\mathrm{N}$ afetam negativamente o crescimento das plantas de algodão, a retenção de capulhos, a produtividade e a qualidade das fibras (REDDY et al., 2004). Além disso, Cisneros e Godfrey (2001) salientam que o excesso de N pode afetar indiretamente a qualidade das fibras, pelo aumento das infestações de pulgões, gerando pegajosidade nos capulhos.

Segundo Rosolem, Zancanaro e Tessaro (2007), aplicações tardias de $\mathrm{N}$ em cobertura não proporcionam aumento de produtividade, devido à indução de um maior crescimento vegetativo, que alonga o ciclo da planta e, consequentemente, incrementa a queda de estruturas reprodutivas.

Em estudos realizados por Link et al. (2005), os autores evidenciaram que informações a campo sobre variabilidade espacial do estado nutricional de plantas são muito valiosas para a prescrição da dose variável de N. Segundo Peñuelas e Filella (1998), a reflectância vegetal é uma eficiente indicadora da quantidade de biomassa e do estado nutricional das plantas, a qual se reflete em produtividade (GROHS et al., 2009). Estudos realizados por Motomyia et al. (2012) relataram a capacidade do sensor óptico (Crop Circle ${ }^{\circledR}$ ACS-210, Holland Scientific, Inc. Lincoln, NE) em avaliar o potencial produtivo do algodoeiro. Resultados semelhantes foram encontrados por Solari et al. (2008), na cultura do milho, e por Bredemeier et al. (2013), na cultura do trigo.

A cultura do algodoeiro, pelo seu elevado valor econômico e pela demanda de ajuste fino na fertilização nitrogenada, apresenta elevado potencial de utilização da dose variada de $\mathrm{N}$ baseada em sensores ópticos. No entanto, são escassos os trabalhos que estudam essa tecnologia no território brasileiro. Nesse contexto, objetivouse com este estudo estabelecer a curva de resposta de produtividade no algodoeiro à aplicação de $\mathrm{N}$ em diferentes áreas, bem como determinar a máxima eficiência econômica e avaliar a eficiência do sensor óptico em estimar o potencial produtivo.

\section{MATERIAL E MÉTODOS}

O presente estudo foi conduzido em três áreas experimentais pertencentes à Fazenda Brasholanda, localizada no oeste baiano, no município de Correntina, com coordenadas geográficas de $13^{\circ}$ $48.580^{\prime} \mathrm{S}$; $46^{\circ} 1.012^{\prime} \mathrm{O}$ e com cerca de $960 \mathrm{~m}$ de altitude. As áreas experimentais apresentavam 0,5 $\mathrm{km}$ entre si. 
A região é caracterizada pelo clima Aw, tropical úmido e seco com estação chuvosa bem definida no verão e estação seca durante o inverno, segundo a classificação de Köppen (1931). Apresenta índice pluviométrico entre $1300-1900 \mathrm{~mm}^{\mathrm{ano}} \mathrm{o}^{-1} \mathrm{e}$ temperatura média anual em torno de $21^{\circ} \mathrm{C}$.

$\mathrm{O}$ delineamento experimental utilizado foi em blocos ao acaso, com sete tratamentos e três repetições nas três áreas experimentais. Cada parcela experimental possuía dimensões de $27 \mathrm{~m} \mathrm{x}$ $27 \mathrm{~m}$, totalizando $729 \mathrm{~m}^{2}$.

A fertilização de semeadura foi realizada de acordo com a análise de solo realizada anteriormente à implantação do experimento sendo aplicado o correspondente a $250 \mathrm{~kg} \mathrm{ha}^{-1}$ do fertilizante formulado (11-52-00) (N-P-K) em todas as áreas, o que corresponde a $27 \mathrm{~kg} \mathrm{ha}^{-1}$ de N e $130 \mathrm{~kg} \mathrm{ha}^{-1}$ de $\mathrm{P}_{2} \mathrm{O}_{5}$. Posteriormente, foi realizada adubação a lanço em superfície com $200 \mathrm{~kg} \mathrm{ha}^{-1} \mathrm{de}$ cloreto de potássio $(\mathrm{KCl})$, o que corresponde a 120 $\mathrm{kg} \mathrm{ha}^{-1}$ de $\mathrm{K}_{2} \mathrm{O}$.

Durante o desenvolvimento da cultura, para as três áreas experimentais, as práticas de manejo e os tratos culturais foram os mesmos e seguiram as recomendações de Freire (2007).

Os tratamentos consistiram em doses de 0,45 , $90,130,150,180$ e $220 \mathrm{~kg} \mathrm{ha}^{-1}$ de $\mathrm{N}$, aplicadas à lanço, utilizando como fonte de $\mathrm{N}$ o fertilizante ureia (46-00-00). A adubação em cobertura foi realizada aos 43 DAS na área 1 e aos 32 DAS na área $2 \mathrm{e}$ área 3. A diferença entre os dias de aplicações entre as áreas deve-se às condições climáticas não terem sido favoráveis para a aplicação do fertilizante no período de 32 DAS na área 1. As doses utilizadas tinham como intuito estabelecer a curva de resposta a $\mathrm{N}$ em função da produtividade para a cultura do algodoeiro e avaliar a eficiência do sensor óptico em diferentes estádios fenológicos. As doses foram sugeridas conforme o manejo adotado pelo produtor e a recomendação foi encontrada na literatura específica da área.

As leituras de IV foram realizadas em três épocas de avaliação. As datas de avaliação, DAS e estádio fenológico da cultura estão descritas no quadro 1. O estádio fenológico foi determinado através da escala do Instituto Agronômico do Paraná (IAPAR), proposta por Marur e Ruano (2001), na qual o estádio B1 corresponde à formação do primeiro botão floral no primeiro ramo reprodutivo, o estádio F1 corresponde à abertura da primeira flor no primeiro ramo reprodutivo e o estádio $\mathrm{C} 1$ corresponde à formação do primeiro capulho no primeiro ramo reprodutivo.

A colheita foi realizada no dia 04 de julho de 2013, e, para a determinação da produtividade, foi realizada coleta manual de capulhos em dois metros lineares de duas fileiras para cada parcela nas três áreas, obtendo-se a massa de capulho com caroço sobre a qual, posteriormente, foi aplicado um fator de multiplicação para obter a produtividade em $\mathrm{kg}$ ha-1.

Os dados obtidos foram submetidos à análise descritiva e de variância (ANOVA) para revelar a existência de significância. As médias foram comparadas pelo teste de tukey $(\mathrm{p}<0,05)$ utilizando o programa estatístico ASSISTAT (SILVA;

Quadro 1. Data das três avaliações, dias após a semeadura e estágio fenológico em que se encontrava a cultura do algodoeiro em cada área experimental (Correntina, Bahia, 2013).

\begin{tabular}{|c|c|c|c|c|c|c|c|c|c|}
\hline & Data & DAS & Estágio & Data & DAS & Estágio & Data & DAS & Estágio \\
\hline Aplicação de N & $18 / 01 / 2012$ & 43 & B1 & $07 / 02 / 2013$ & 32 & V4 & $07 / 02 / 2013$ & 32 & V4 \\
\hline $1^{a}$ Avaliação & $07 / 02 / 2013$ & 63 & $\mathrm{~F} 1$ & $19 / 02 / 2013$ & 45 & B1 & $19 / 02 / 2013$ & 45 & B1 \\
\hline $2^{\mathrm{a}}$ Avaliação & $19 / 02 / 2013$ & 75 & F4 & $12 / 03 / 2013$ & 57 & $\mathrm{~F} 1$ & $12 / 03 / 2013$ & 57 & F1 \\
\hline $3^{\mathrm{a}}$ Avaliação & $12 / 03 / 2013$ & 97 & $\mathrm{C} 4$ & $04 / 04 / 2013$ & 80 & F8 & $04 / 04 / 2013$ & 80 & F8 \\
\hline Colheita & $04 / 07 / 2013$ & 211 & & $04 / 07 / 2013$ & 180 & & $04 / 07 / 2013$ & 180 & \\
\hline
\end{tabular}


AZEVEDO, 2009). Para a análise de regressão entre os parâmetros avaliados foi utilizado o software Sigma Plot 11.

Para se determinar a dose de MET, utilizou-se a equação ajustada entre produtividade e doses de $\mathrm{N}$ fertilizante. Já para a determinação da máxima eficiência econômica (MEE), foi utilizada a metodologia proposta por Raij (1991), igualandose a primeira derivada da equação de regressão correspondente à produtividade no valor zero, e a relação entre preços do insumo ( $\mathrm{R} \$$ por $\mathrm{kg}$ de $\mathrm{N}$, na forma de ureia) e do produto ( $\mathrm{R} \$$ por $\mathrm{kg}$ de algodão em caroço), considerando-se os preços vigentes no estado da Bahia, em junho de 2013. Nesse caso, o custo do $\mathrm{kg}$ de $\mathrm{N}$ foi de $\mathrm{R} \$ 2,22$, e o valor do $\mathrm{kg}$ de algodão em caroço foi de $\mathrm{R} \$ 1,73$. A quantificação da dose de $\mathrm{N}$ que corresponde à MEE foi obtida utilizando-se a Equação 1.

$\mathrm{D}_{\mathrm{N}}=(\mathrm{b}-\mathrm{F}) /(2 * \mathrm{a})$

em que,

$\mathrm{D}_{\mathrm{N}}=$ dose de nitrogênio $\left(\mathrm{kg} \mathrm{ha}^{-1}\right)$;

$\mathrm{b}=$ coeficiente linear.

$\mathrm{F}=$ relação entre os preços do insumo e do produto.

$\mathrm{a}=$ coeficiente angular

\section{RESULTADOS E DISCUSSÃO}

Nas três áreas avaliadas, as doses de $\mathrm{N}$ afetaram de forma quadrática e significativa a produtividade do algodoeiro (Figura 1a, 1b, 1c), indicando que, a partir de uma determinada dose, o excesso de $\mathrm{N}$ passa a ser prejudicial para o desenvolvimento da cultura, como descrito anteriormente por Hutmacher et al. (2004).

Em relação à área 1 (Figura 1a), de acordo com a equação ajustada, a dose de $\mathrm{N}$ que alcançou a máxima produtividade, ou seja, a MET foi de $169 \mathrm{~kg} \mathrm{ha}^{-1}$ de N, a qual atingiu a produtividade de $7.133 \mathrm{~kg} \mathrm{ha}^{-1}$ de algodão. Considerando a MEE como a relação entre o preço do insumo e preço do produto, a dose indicada foi de $164 \mathrm{~kg} \mathrm{ha}^{-1}$ de N, o que resultaria, de acordo com a equação ajustada, em $7.129 \mathrm{~kg} \mathrm{ha}^{-1}$ de algodão em carroço.
Para a área 2, a MET foi atingida com a dose de $146 \mathrm{~kg} \mathrm{ha}^{-1}$ de $\mathrm{N}$, que resultou na máxima produtividade, de $4.948 \mathrm{~kg} \mathrm{ha}^{-1}$ de algodão (Figura 1b). Já a MEE para essa mesma área foi de $139 \mathrm{Kg} \mathrm{ha}^{-1}$ de $\mathrm{N}$, alcançando a produtividade de $4.943 \mathrm{~kg} \mathrm{ha}^{-1}$ de algodão. Com relação à área 3 , a MET foi igual a $183 \mathrm{~kg} \mathrm{ha}^{-1}$ de $\mathrm{N}$ e resultou em $4.694 \mathrm{~kg} \mathrm{ha}^{-1}$ de algodão (Figura 1c). A MEE dessa área experimental foi de $167 \mathrm{~kg} \mathrm{ha}^{-1} \mathrm{de} \mathrm{N}$, alcançando a produtividade de $4.684 \mathrm{~kg} \mathrm{ha}^{-1}$. Na área 3 foi observado o mais elevado coeficiente de determinação entre os três experimentos $\left(R^{2}=70\right)$, apresentando elevada resposta do algodoeiro já para as primeiras doses de nitrogênio.

A variabilidade espacial em uma mesma área agrícola ou em distintas áreas pronuncia-se, não só na produtividade das culturas, como também na necessidade de adubação para suprir as exigências nutricionais da planta. Neste estudo, verificouse pouca diferença entre a dose de $\mathrm{N}$ necessária para atingir a MEE dos experimentos 1 e 3 e a produtividade máxima atingida em cada um deles. Assim, enquanto no experimento 1, considerado de elevada produtividade, a MEE foi de $164 \mathrm{~kg} \mathrm{ha}^{-1}$ de $\mathrm{N}$ para alcançar $7.129 \mathrm{~kg} \mathrm{ha}^{-1}$ de algodão, no experimento 3 , considerado de baixo rendimento, a MEE foi de $167 \mathrm{~kg} \mathrm{ha}^{-1} \mathrm{deN}$ para uma produtividade de $4684 \mathrm{~kg} \mathrm{ha}^{-1}$ de algodão. Nesse caso, embora a MEE tenha sido semelhante entre os experimentos, a produtividade foi $34 \%$ maior no experimento 1 que no 3.

Os resultados verificados neste estudo corroboram os encontrados por Motomyia et al. (2012), que reportaram incremento na produtividade do algodoeiro com as doses de $\mathrm{N}$ aplicadas, ajustando-se a um modelo quadrático, em que a máxima produtividade, conforme a derivação da equação de regressão, seria atingida com a dose de $195 \mathrm{~kg} \mathrm{ha}^{-1}$.

A elevada demanda de $\mathrm{N}$ pelo algodoeiro para alcançar elevadas produtividades sugere que a quantidade de $\mathrm{N}$ fornecida pelo solo não é suficiente para atender à necessidade da cultura (MOTOMYIA et al., 2012). Na maioria dos experimentos realizados na região do cerrado, em

\section{REVENG $57-64 p$.}


solos de textura média a argilosa e em condições de sequeiro, respostas econômicas foram obtidas com doses de 100 a $130 \mathrm{~kg} \mathrm{ha}^{-1}$ de $\mathrm{N}$ em cobertura. Ainda, respostas a doses mais elevadas podem ocorrer em função da baixa eficiência agronômica do N (MAPA, 2006).

O ajuste quadrático da produtividade demonstra que a aplicação de elevadas doses de $\mathrm{N}$ tem um efeito negativo no desenvolvimento do algodoeiro. Esse resultado é decorrente do aumento da absorção de $\mathrm{N}$ e pode resultar em desequilíbrio nutricional, induzindo ao excesso de desenvolvimento vegetativo (MAPA, 2003).

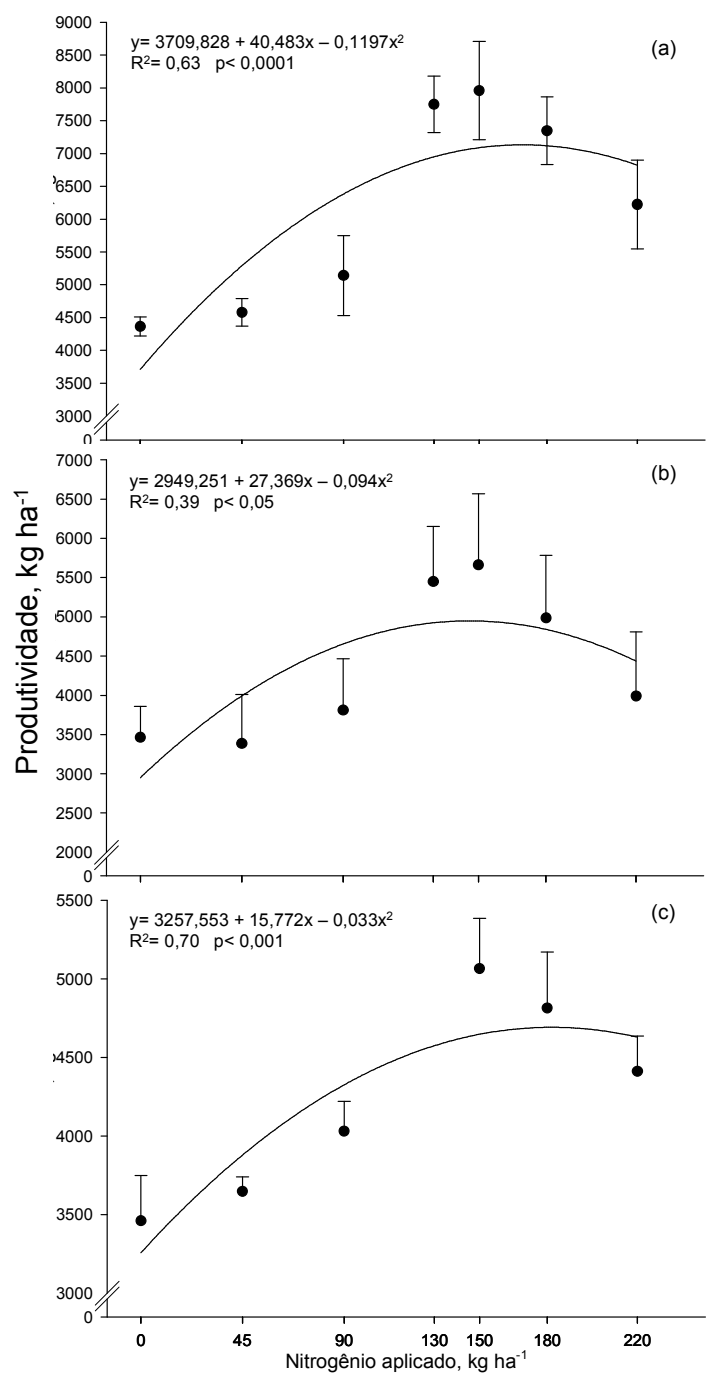

Figura 1. Efeito das doses de $\mathrm{N}$ na produtividade do algodoeiro em caroço para a área 1 (a), área 2 (b) e área 3 (c). (Correntina, Bahia, 2013).
Neste estudo, as leituras de IV foram capazes de predizer a produtividade da cultura. Resultados semelhantes foram anteriormente reportados por Motomyia et al. (2012). Esse resultado pode ser observado na Figura 2, para a área 1, em que a leitura de IV realizada no estádio F1 (Figura 2a) possibilitou a estimativa da produtividade da cultura com ajuste quadrático.

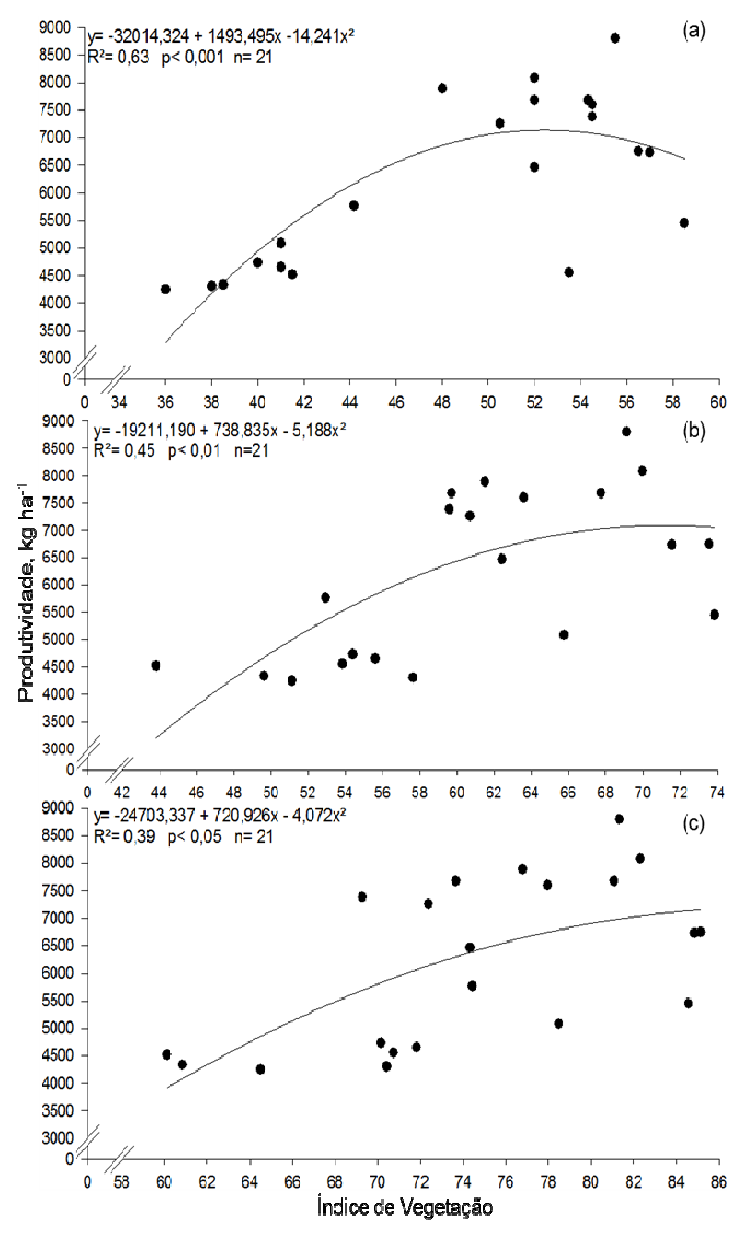

Figura 2. Relação entre o IV e a produtividade do algodão para a primeira avaliação (a), segunda avaliação (b) e terceira avaliação (c) referentes a área 1 (Correntina, Bahia, 2013).

Destaca-se, ainda, que a leitura de IV foirealizada no estádio F1, concordando com o proposto por Fridgen e Varco (2004). De forma análoga ao verificado na área 1, a área 2 apresentou correlação entre o IV obtido no estádio $\mathrm{F} 1 \mathrm{e}$ a produtividade do algodoeiro (Figura 3b). Entretanto, as leituras 
realizadas nos demais estádios não apresentaram relação com a produtividade da cultura (Figuras 3a e 3c).

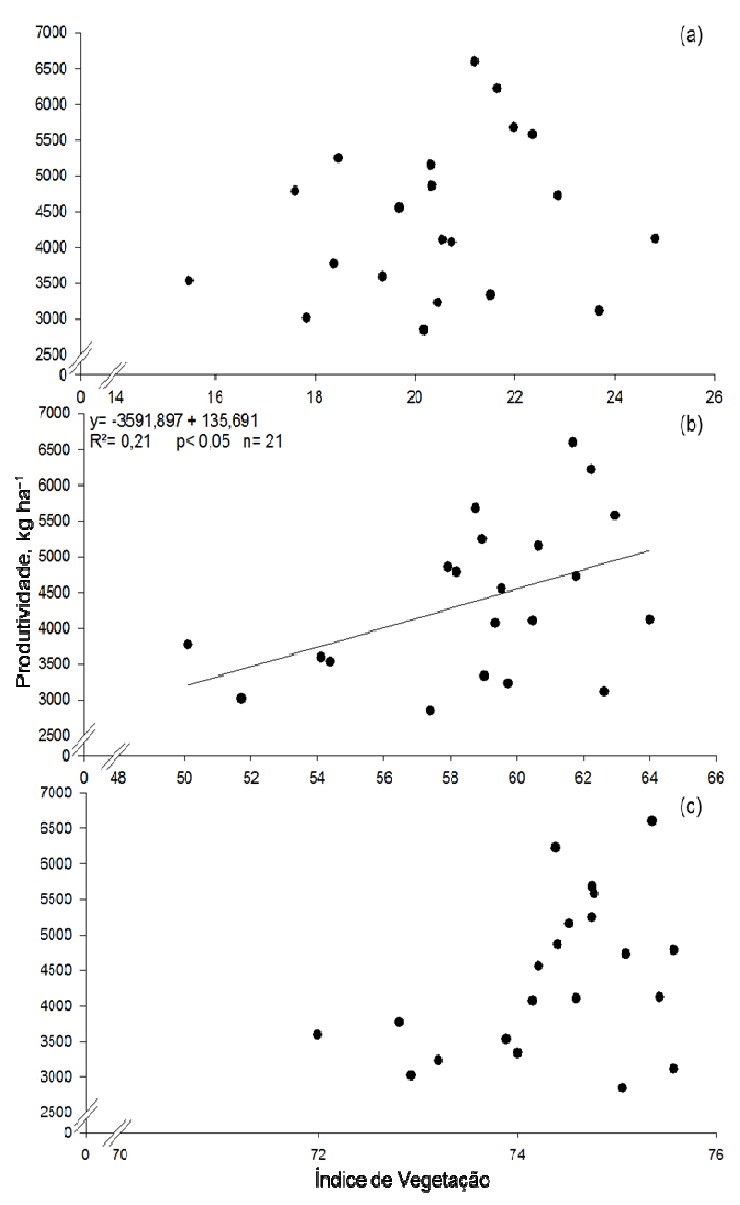

Figura 3. Relação entre o IV e a produtividade do algodão para a primeira avaliação (a), segunda avaliação (b) e terceira avaliação (c) referentes a área 2 (Correntina, Bahia, 2013).

O mesmo comportamento foi encontrado para a área 3, aonde o estádio $\mathrm{F} 1$ apresentou maior correlação (Figura 4b) entre os três estádios avaliados.

Buscaglia e Varco (2002) e Motomyia et al. (2012), avaliando o uso do N Sensor na determinação do IV em plantas de algodoeiro, reportaram maior relação nas leituras realizadas no estádio F1, referente ao início da floração da cultura. Os resultados obtidos no presente estudo vão ao encontro dos trabalhos citados anteriormente, notadamente nas três áreas avaliadas.

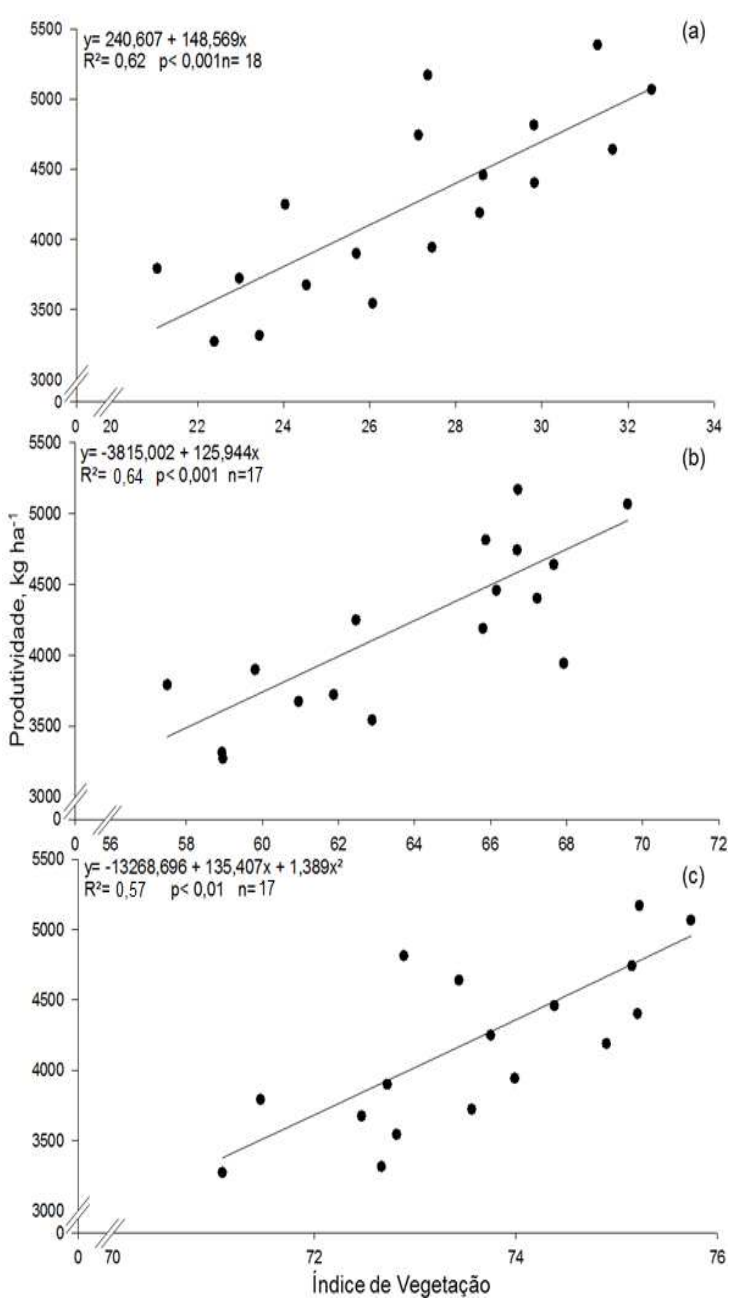

Figura 4. Relação entre o IV e a produtividade do algodão para a primeira avaliação (a), segunda avaliação (b) e terceira avaliação (c) referentes a área 3 (Correntina, Bahia, 2013).

\section{CONCLUSÕES}

- A produtividade da cultura do algodoeiro foi positivamente influenciada pelas doses de $\mathrm{N}$ aplicadas, apresentando ajuste quadrático nas três áreas investigadas. A produção variou de $3.709 \mathrm{~kg} \mathrm{ha}^{-1}(\mathrm{sem} \mathrm{N})$ a $7.133 \mathrm{~kg} \mathrm{ha}^{-1}$ (dose para a MET) para a área 1 , de $2.949 \mathrm{~kg} \mathrm{ha}^{-1}$ (sem N) a $4.948 \mathrm{~kg} \mathrm{ha}^{-1}$ (dose para a MET) para a área 2 e de $3.257 \mathrm{~kg} \mathrm{ha}^{-1}(\mathrm{sem} \mathrm{N})$ a $4.694 \mathrm{~kg}$ $\mathrm{ha}^{-1}$ (dose para a MET) para a área 3 ;

- O sensor apresentou elevada eficiência em estimar o potencial produtivo da cultura, apresentando maior eficiência quando a cultura encontrava-se no início do florescimento. 


\section{REFERÊNCIAS BIBLIOGRÁFICAS}

BREDEMEIER, C.; VARIANI, C.; ROSA, A.T. Estimativa do potencial produtivo em trigo utilizando sensor óptico ativo para adubação nitrogenada em taxa variável. Ciência Rural, Santa Maria, v.43, n.7, p.1147-1154, 2013.

BUSCAGLIA, H.J.; VARCO, J.J. Early detection of cotton leaf nitrogen status using leaf reflectance. Journal of Plant Nutrition, Austin, v.25, n.9, p. 2067-2080, 2002.

CARVALHO, M.C.S.; FERREIRA, G.B.; STAUT, L.A. Nutrição, calagem e adubação do algodoeiro. In: FREIRE, E. C. Algodão no cerrado do Brasil. Brasília: Associação Brasileira dos Produtores de Algodão, 2007. p.581-647.

CISNEROS, J.J.; GODFREY, L.D. Effects of nitrogen fertility. California. In Proc. Beltwide Cotton Conferences, New Orleans, v.1, p.961-964, 2001.

EMBRAPA. Sistema Brasileiro de Classificação de Solos. 2. ed. Rio de Janeiro: Embrapa- CNPS, 2006. 400p

FILHO, J.L.S.; PEDROSA, M B.. Resultados de pesquisas com a cultura do algodão no oeste e sudoeste da Bahia, safra 2003/2004. Campina Grande: Embrapa Algodão, 2004. (Documentos, 133)

FREIRE, E.C. Algodão no cerrado do Brasil. 1. ed. Brasilia: Abrapa, 2007. v.1.918p .

FRIDGEN, J.L.; VARCO J.J. Dependency of cotton leaf nitrogen, chlorophyll, and reflectance on nitrogen and potassium availability. Agronomy Journal, Madison, v.96, n.1, p.63-69, 2004.

GROHS,D.S.;BREDEMEIER,C.; MUNDSTOCK, C.M.; POLETTO, N. Modelo para estimativa do potencial produtivo em trigo e cevada por meio do sensor GreenSeeker. Engenharia Agrícola, Jaboticabal, v.29, v.1, p. 101-112, 2009.
HUTMACHER, R.B.; TRAVIS, R.L.; RAINS, R.N. Response of recent Acala cotton cultivars to variable nitrogen rates in the San Joaquin valley of California. Agronomy Journal, Madison, v.96, p. 48-62, 2004.

JASPER, J.; REUSCH, S.; LINK, A. Active sensing of the $\mathrm{N}$ status of wheat using optimized wavelength combination-impact of seed rate, variety and growth stage. In: VAN HENTEN, E.J.; GOENSE, D.; LOKHORST, C. (ed.). PRECISION AGRICULTURE, 7., 2009, Wageningen. Proceedings... Wageningen, The Netherlands: $7^{\text {th }}$ European conference on precision agriculture. Academic Publishers, 2009. p.23-30.

KÖPPEN, W.P. Grundriss der Klimakunde. Berlin: Walter de Gruyter, 1931. 388 p.

LINK, A.; JASPER, J.; REUSCH, S. Suitability of different crop parameters for the determination of site-specific nitrogen fertilizer demand. In: STAFFORD, J.V. (ed.). PRECISION AGRICULTURE, 5., 2005, Wageningen. Proceedings... Wageningen, The Netherlands: $5^{\text {th }}$ European Conference on Precision Agriculture. Academic Publishers, 2005. p.297-302.

MALIK, M.N.A.; EVENSON, J.P.; EDWARDS, D.G. The effect of level of of nitrogen nutrition on carliness in upland cotton (Gossypium hirstum L.). Australian Journal of Agricultural Research, New Zeland, v.29, p. 1213-1221. 1978.

MAPA. Ministério da Agricultura, Pecuária e Abastecimento. Calagem e Adubação do Algodoeiro no Cerrado. Circular Técnico, n. 92, Campina Grande, 2003. 81p

MAPA: Ministério da Agricultura, Pecuária e Abastecimento. Manejo da adubação Nitrogenada do algodoeiro no Sistema plantio direto com Integração lavoura-pecuária, no Cerrado de Goiás. Circular Técnico, n. 199, Campina Grande, 2006. 70p

MARUR, C.J.; RUANO, O.A. Reference system for determination of developmental stages of 
upland cotton. Revista Brasileira de Oleaginosas e Fibrosas, Campina Grande, v.5, n.2, p. 313-317, 2001.

MOTOMYIA V.; MOLIN, J.P.; MOTOMYIA, W.R.; BISCARO, G.A. Diagnose nutricional com o uso de sensor óptico ativo em algodoeiro. Revista Brasileira de Engenharia Agrícola e Ambiental, Campina Grande, v.16, n.11, p. 1159-1165, 2012.

PEÑUELAS, J.; FILELLA, I. Visible and nearinfrared reflectance techniques for diagnosing plant physiological status. Trends in Plant Science, Berkeley, v.3, n.4, p.151-156, 1998.

RAIJ, B.van. Fertilidade do solo e adubação. Piracicaba: Agronômica Ceres, Associação Brasileira para a Pesquisa da Potassa e do Fosfato, 1991. 343p.

REDDY, V.S.; DAY, I.S.; THOMAS, T.; REDDY, A.S.N.; KIC, a novel $\mathrm{Ca}^{2+}$ binding protein with one EF-hand motif, interacts with a microtubule motor protein and regulates trichome morphogenesis. Plant Cell, Florida, v.16, p.185-200, 2004.

ROSOLEM, C.A.; ZANCANARO, L.Z.; TESSARO, L.C. Nitrogênio e enxofre na cultura do algodoeiro. In: YAMADA, T.; ABDALLA, S.R.S.;
VITTI, G.C. Nitrogênio e enxofre na agricultura brasileira. Piracicaba: IPNI, 2007. p.321-347.

SILVA, F.A.S.; AZEVEDO, C.A.V. Principal components analysis in the software assistatstatistical assistance. In: WORLD CONGRESS ON COMPUTERS IN AGRICULTURE, 7., 2009, San Jose. Proceedings... San Jose: St. Joseph: ASABE, 2009. 5 CD-ROM.

SILVA, N.M.; CARVALHO, L.H.; KONDO, J.I.; SABINO, J.C.; PETTINELLI JUNIOR, A.; LANDELL, M.G.A. Efeitos da adubação nitrogenada e de regulador de crescimento na cultura algodoeira. In: REUNIÃO NACIONAL DO ALGODÃO, 7., Cuiabá, 1993. Resumos... Cuiabá: EMPAER-MT/EMBRAPA/CNPA, 1993. p.215.

SOLARI, F.J.; SHANAHAM, J.; FERGUSON, R.B.; SCHEPERS, J.S.; GITELSON, A.A. Active sensor reflectance measurements of corn nitrogen status and yield potential. Agronomy Journal, Madison, v.100, p.571-579, 2008.

STAUT, L.A.; KURIHARA, C.H. Calagem e adubação. In: Algodão: tecnologia de produção. Dourados: Embrapa Agropecuária Oeste, 2001. p.19 